\title{
Integrating Figure and Finish Measurements with Surface Profiling Instruments*
}

\author{
Peter Z. Takacs \\ Brookhaven National Laboratory \\ Upton, NY 11973-5000 \\ $516 / 282-2824$ \\ and \\ Eugene L. Church \\ USA ARDEC, Picatinny, NJ 07806-5000 \\ 201/724-7317
}

Recently developed instrumentation and measurement techniques now make it possible to extend profilometry into the realm of surface figure measurement. This view of surface figure errors differs significantly from the traditional optician's approach.

*This research was supported by the U. S. Department of Energy:

Contract No. DE-AC02-76CH00016.

\section{DISCLAIMER}

This report was prepared as an account of work sponsored by an agency of the United States Government. Neither the United States Government nor any agency thereof, nor any of their employees, makes any warranty, express or implied, or assumes any legal liability or responsibility for the accuracy, completeness, or usefulness of any information, apparatus, product, or process disclosed, or represents that its use would not infringe privately owned rights. Reference herein to any specific commercial product, process, or service by trade name, trademark, manufacturer, or otherwise does not necessarily constitute or imply its endorsement, recommendation, or favoring by the United States Government or any agency thereof. The views and opinions of authors expressed herein do not necessarily state or reflect those of the United States Government or any agency thereof. 


\title{
Integrating Figure and Finish Measurements with Surface Profiling Instruments
}

\author{
Peler Z. Takiles \\ Bromkhaven Nationad Lahoratury \\ Upton, NY 11973-5(KX) \\ $516 / 282-2824$ \\ Eugene L. Church \\ ISSA ARIDLC, Picatinny, NJ O)7R(1)6-5(KK) \\ $2(1) 1 / 724-7317$$$
\text { in sts }
$$

\begin{abstract}
Conventional figure meisurement techniques are inadequate for lesting aspheres for grazing incidence applications. Conventional lechniques are hest suited for upteal components in the shape of thats, spheres, or conical surfaces of revolution, used mainly in mormal incidence applications. These optics usually have their symmetry axis coincident with the lecal surfate normal direction. (iratzing incidence optics, wa the other hand, are usually cylindrical, toroidal, or ellipsoidal in shape, with the symmetry axis intersection far outside the clear aperture. Sisch surfaces are not axisymmetric when viewed allong doeir surface normals. l'hey are highly anamorphic, having vastly different curvatures in the two directions parallel and perpendicular to the symmetry axis. It is extremely challenging to test these uptical components during fabrication to insure that they indeed meet the specifications for figure and finish quality. It is hecause of the extreme difficulties involved in developing reliable tests with conventional interferometric techniques that we decided to use profiling techniques to characterize the figure and tinish of synchrotron radiation (SR) optics.
\end{abstract}

SR optics are generally used in grazing incidence applications where goxd control over image quality is required only in the plane of incidence. For example, light that is scattered or deflected along the length of an entrance or exit slit inside a monochromator is aceeptahle, hut light that is scattered or deflected perpendicular to the slit must be minimized. At grating incidence angles ("hurch $|1|$ has shown that surface errors in the plane of incidence are respensible for prexducing much more scattered light than are surface errors in the transwerse direction. Tolerances on optical fabrication thus need not he the same in all directions on SR optics. What is of primary concern to SR users are the axial finthh and figure errors on cylindrical optics.

Until about ten years agn it was very difficult 10 routinely measure the roughness of optical surfaces, especially on large, full-sized grazing incidence mirrors. The only quastitative technique available was by stylus profiler $[2,3]$. Development of a commercial micro phase-measuring interferometer (PMI) early in the last deciade has made it possible to measure the axial roughness of large cylindrical aspheres rapidly and accurately [4]. Accuracy, however, in surface roughness measurement requires one to have a thorough understanding of the performance limitations of the measuring instrument. A significant effort has heen made to characterize the error sources in PMI profiling instruments, and models have been developed to correct for inherent limitations in each optical system [5-9]. We have developed analysis techniques that compute the power spectral density of the surface profile and use it to predict the distribution of scattered light from the surface. A significant effort has gone into the development of the analysis code to insure that artifacts introduced into the data by the optical system or the analysis process are minimized.

In order to deal with the figure measurement problem on large (up to 1 meter long) SR optics, we developed a scanning profiling instrument, the Long Trace Profiler (LTP). [10, 11] This instrument has enabled us (1) measure the axial shape of large aspheric surfaces with accuracies in the range of $1 / 10 \%$ ) of a wavelength of visihle light, i.e. with RMS error bars of less than 10 nanometers. The range of spatial periods sampled by this instrument complements that of the PMI: the LTP covers the 1 meter $101 \mathrm{~mm}$ spatial peried range, while the PM! instrument covers the $5 \mathrm{~mm}$ to $10 \mathrm{~mm}$ range. The region of overlap in the frequency domain between the (wo instruments is very important in assessing the quality of data from each instrument.

The use of a profiling instrument to measure what is traditionally regarded as "figure" on an optical surface has required an unconventional approach to quamtifying large-scale surface shape errors. We use the same analysis techniques for macroroughness as we do for microroughness, that is, we analyze the surface profi'n in terms of its power spectrum. One major result to come out of this work is the removal of the artificial distinction between 
figure and finish on an oplical surface. We have develuped a theoretical mokdel that predicts the core image intensity and scaltered light distribution from knowledge of the source coherence properties, detector size, and spectrum of the surface irregularities over the 5 decade range covered by the (wo) profiling instruments $|12-14|$ Another significant result of this work with profiling instruments is the ohservation that most polished optical surfaces tend to have spectral distributions that follow inverse puwer law functions with exponents in the range of 1.2 [0 $1.5 \mid 1.5]$. Such behavior over such a large range of spatial frequencies is indicative of a self-affine fractal process. Microscopic models of surface properties explaining this behavior are currenty under investigation.

\section{References}

1. E.L. (hurch, "The Role of Surface Topography in X-ray Scattering," Procedings of the SPII: 184, 196-202 (1979)

2. J.M. EIson at.d I.M. Benneth, Relation betwe'en the angular dependence of scattering and the statistical properties of oplical sirrfice's. Journal of the Optical Society of America, 69, p. $31-47$ (1979).

3. J.M. Bennell and J.H. Dancy, Stylus profiling instrument for medsuring statisticul properties of smonoth optical surfuces. Applied (Optics. 20. p. 1785-18(1)2 (1981)

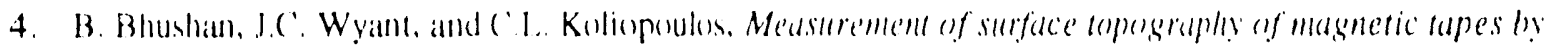

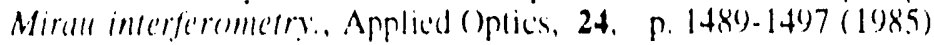

5. E.I. Church and P.Z. 'Takates. Use' of un opticul-profiling instrument for the measurement of the figure and finish of optical-gucality surfuces. Weas 109: p. 241-257, (1986).

6. E.I. Church and P.Z. Takis's, "Effects of the uptical transfer function in surface profile measurements," in Surface Characteriation and Testing II, J.E. (iricvenkamp, M. Young, ed., Proc. SPIE 1164, 46-59) (1989)

7. E.L. Church and P.L. Takac's, "Instrumental effects in surface finish measurement." in . Surface Medsureme'nt and Characterization, J.M. Bennell, ed., Proce. SPll: 1009, 46-5.5(1989)

8. E.I. (Church, "The precision meanurement and characterization of surface finish," Proc. SPII: 429, 86(198,3)

9. J.F. Biegen, Calibration regmirements for Mirulu and Linnik microscope interferometers. Applied Optics, 28, p. $1972-1974(1989)$.

10. P.Z. Takacs, S.-C.K. Feng, E.L. Church, S.-N. Qian, and W.-M. Liu, "Long trace profile measurements on cylindrical aspheres," in Adrances in Fabrication and Metrology for Optics and Large Optics, J.B. Arnold, R.A. Parks, ed., Proc. SPIE 966, 354-364 (1989)

11. P.Z. Takacs, K. Furenlid, R. I) Biasse, and E.L. Church, "Surface topography measurements over the 1 meter 10 10 micrometer spatial period bandwidth," in Surface Characterization and Testing II. J.E. Grievenkamp. M. Young, ed., Proc. SPIE 1164, 2(1)3-211 (1989)

12. E.L. Church and P.Z. Takacs, "Prediction of mirror performance from laboralory measurements," in $X \cdot r u y / E U V$ Optics for Astronomy and Microscopy, R.B. Hoover, ed., Proc. SPIE 1160, 323-336 (1989)

13. E.L. Church and P.Z. Takacs. "Specification of surfuce finish in terms of system performance." in Surface Rolghness and Scattering (1992) Technical Digest., Tucson, AZ: OSA (1992).

14. P.Z. Takacs and E.L. Church, Figure and Finish Measurements of Grazing Incidence Mirrors, in Nucl. Insts. \& Meth. A291, p. 253-264, North-Hulland (199()).

15. E.L. Church, Fractal surface finish. Applicd Optics, 27 (No, 8): p. 1518-1.526 (1988). 

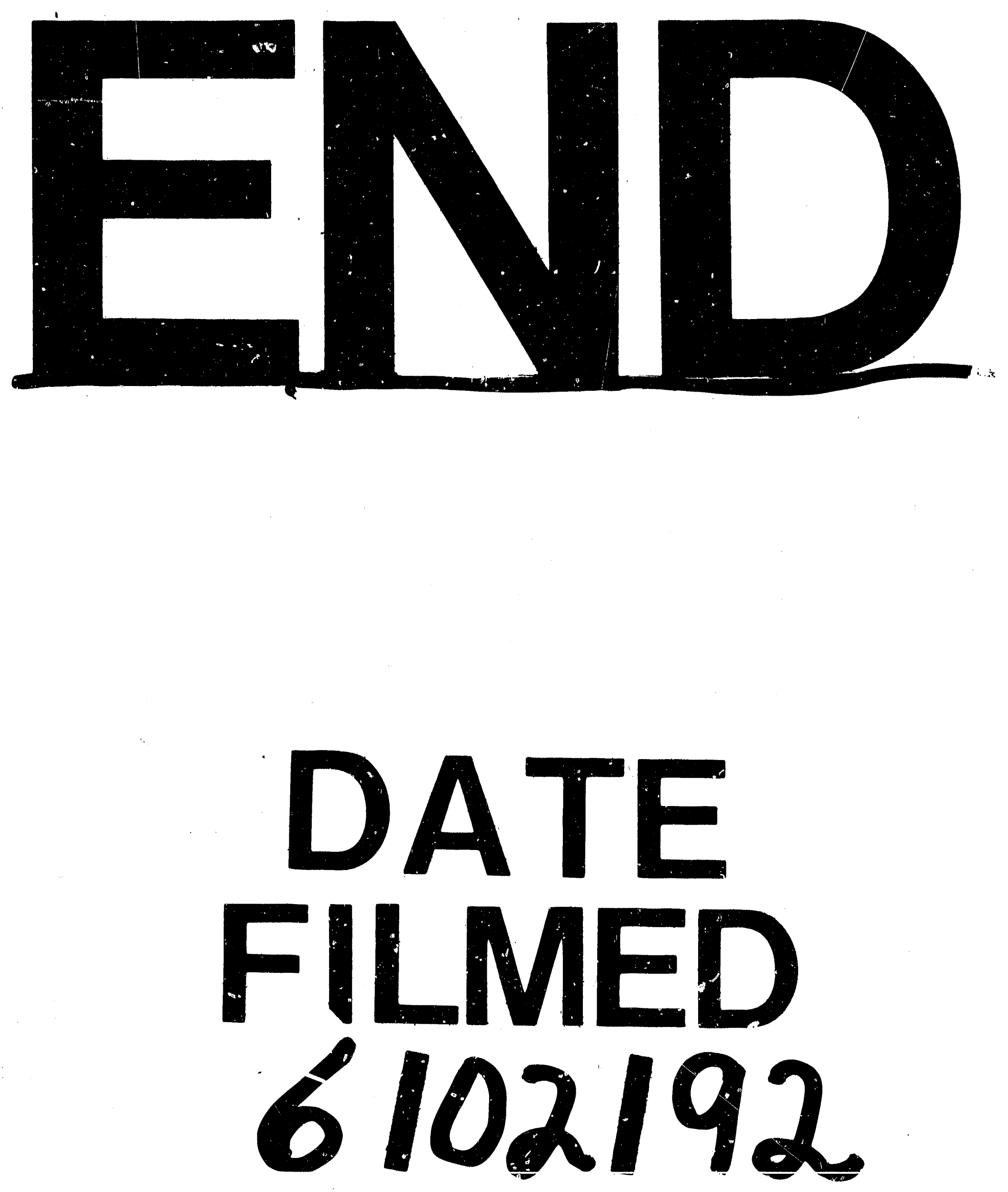
1 